\title{
QUEBRA DE DORMÊNCIA DE SEMENTES DO FEIJÃO-MUNGO'
}

\author{
SHIOW SHONG LIN²
}

RESUMO - No laboratório de sementes da Universidade Federal de Santa Catarina, Florianópolis, $\mathrm{SC}$, avaliou-se o efeito de tratamentos pré-germinativos sobre a quebra de dormência em sementes do feijão-mungo (Vigna radiata L., Leguminosae). As sementes de quatro cultivares (Pusa 9173, ML 267, NM 51 e Chun Nam 4) foram submetidas aos tratamentos com água quente $\left(80^{\circ} \mathrm{C}\right)$, álcool à temperatura ambiente e ácido sulfúrico concentrado. Os tratamentos com ácido sulfúrico concentrado foram os que apresentaram as maiores porcentagens de germinação. Os tratamentos com imersão em álcool durante 5 e 10 minutos, e em água à temperatura de $80^{\circ} \mathrm{C}$ por 5 e 10 minutos mostraram-se eficientes, atingindo percentuais de germinação superiores aos da testemunha. No tratamento de imersão em água à temperatura de $80^{\circ} \mathrm{C}$ por 15 minutos, verificou-se acentuada mortalidade de sementes, reduzindo drasticamente o percentual de germinação. O tratamento com ácido sulfúrico concentrado, por 6 minutos, possibilitou uma porcentagem de germinação de 96\%, sendo assim o mais indicado. As cultivares Pusa 9173, ML 267 e NM 51 apresentaram maior intensidade de dormência em comparação à cultivar Chun Nam 4.

Termos para indexação: tratamento químico, Vigna radiata.

\section{DORMANCY SUPPRESSION IN MUNGBEAN SEED}

\begin{abstract}
The effects of pre-germination treatments on the dormancy of mungbean seeds were evaluated in the seed laboratory of the Universidade Federal de Santa Catarina, Florianópolis, SC, Brazil. Seeds of four mungbean (Vigna radiata L., Leguminosae) cultivars (Pusa 9173, ML 267, NM 51 and Chun Nam 4) were submitted to treatments with hot water $\left(80^{\circ} \mathrm{C}\right)$, alcohol at room temperature and concentrated sulphuric acid. The sulphuric acid treatments were the most effective treatments in terms of germination percentage. The immersion of seeds in alcohol at room temperature during 5 and 10 minutes and seeds immersed in hot water $\left(80^{\circ} \mathrm{C}\right)$ during 5 and 10 minutes showed results significantly higher than the control. The hot water $\left(80^{\circ} \mathrm{C}\right)$ treatment during 15 minutes caused pronounced seed mortality and reduced drastically the germination percentage. The sulphuric acid treatment during 6 minutes attained the germination percentage of $96 \%$, which was the most promising method. The cultivars Pusa 9173, ML 267 and NM 51 showed more intensive dormancy levels than the cultivar Chun Nam 4.
\end{abstract}

Index terms: chemical treatment, Vigna radiata.

\section{INTRODUÇ̃̃O}

O feijão-mungo, por ser uma leguminosa anual de fácil adaptação aos climas tropicais e subtropicais, e por atingir produtividades em torno de $2.000 \mathrm{~kg} / \mathrm{ha}$, apresenta-se como importante fonte de alimentação. Ele representa uma importante fonte protéica para a população asiática, onde o seu cultivo está muito difundido.

\footnotetext{
${ }^{1}$ Aceito para publicação em 24 de agosto de 1998.

${ }^{2}$ Eng. Agr., Ph. D., Prof. Titular, CCA/UFSC, Caixa Postal 476, CEP 88040-900 Florianópolis, SC. E-mail: shiolin@cca.ufsc.br
}

No Brasil, é consumido, principalmente, na forma de broto-de-feijão; a maioria das cultivares usadas apresenta sementes miúdas e de coloração verde, motivo pelo qual é bastante conhecido como mungo-verde. Essa leguminosa é rica em proteína, vitamina $\mathrm{B}$ e ferro, apresentando maior produtividade que a do feijoeiro comum. Tais características estimulam a difusão do seu cultivo e consumo, principalmente entre os pequenos produtores (Duque et al., 1987).

O broto-de-feijão, conhecido pelos japoneses como "moyashi", é obtido por intermédio da germinação das sementes do feijão-mungo sob condições 
controladas, ficando pronto para o consumo em 5 dias. A alta produtividade do "moyashi" depende principalmente da alta porcentagem de germinação da semente, bom vigor, e baixa porcentagem de sementes duras (Duque et al., 1987). A uniformidade de emergência das sementes em campo é um dos principais fatores de sucesso da agricultura moderna, no que se refere a culturas para produção de grãos.

Lin \& Ferrari (1993), estudando diversas linhagens do feijão-mungo, observaram que algumas apresentavam dormência, devida à impermeabilidade dos seus tegumentos à água (sementes duras).

A eliminação da dormência em sementes duras consiste em provocar alterações na estrutura do tegumento, que possam permitir a entrada de água. Isto seria conseguido mediante a aplicação de tratamento adequado, conforme o tipo de semente; dentre eles, pode-se citar: escarificação mecânica, tratamento com ácido sulfúrico, imersão em água quente, tratamento com solventes e incisão com lâmina ou estilete (Toledo \& Marcos Filho, 1977).

Este trabalho foi realizado com o objetivo de avaliar a eficiência de vários tratamentos pré-germinativos nas sementes do feijão-mungo e estabelecer métodos para solucionar os problemas de atraso e desuniformidade de germinação.

\section{MATERIAL E MÉTODOS}

$\mathrm{O}$ experimento foi conduzido no Laboratório de Sementes do Departamento de Fitotecnia do Centro de Ciências Agrárias (CCA) da Universidade Federal de Santa Catarina (UFSC), no período de março a julho de 1994.

Foram utilizadas sementes das cultivares Pusa 9173, NM 51, ML 267 e Chun Nam 4, colhidas em dezembro de 1993, provenientes de plantio realizado na área experimental do CCA/UFSC, localizada na Fazenda da Ressacada em Florianópolis, SC.

As sementes foram selecionadas objetivando amostras uniformes, isentas de sementes doentes, mal formadas, quebradas ou danificadas pelo ataque de insetos. Para a obtenção da quantidade necessária à realização dos tratamentos, juntamente com a seleção, as sementes foram contadas, sendo, em seguida, acondicionadas em sacos de plástico.

Foram aplicados os seguintes tratamentos prégerminativos: $\mathrm{T}_{1}$ - Imersão em água à temperatura de $80^{\circ} \mathrm{C}$, por 5 minutos; $\mathrm{T}_{2}$ - Imersão em água à temperatura de $80^{\circ} \mathrm{C}$, por 10 minutos; $\mathrm{T}_{3}$ - Imersão em água à temperatura de $80^{\circ} \mathrm{C}$, por 15 minutos; $\mathrm{T}_{4}$ - Imersão em álcool à temperatura ambiente, por 5 minutos; $\mathrm{T}_{5}$ - Imersão em álcool à temperatura ambiente, por 10 minutos; $\mathrm{T}_{6}$ - Imersão em álcool à temperatura ambiente, por 15 minutos; $\mathrm{T}_{7}$ - Imersão em ácido sulfúrico concentrado, por 3 minutos; $\mathrm{T}_{8}$ - Imersão em ácido sulfúrico concentrado, por 6 minutos; $\mathrm{T}_{9}$ - Imersão em ácido sulfúrico concentrado, por 9 minutos; $\mathrm{T}_{10}$ - Testemunha (sementes não submetidas a qualquer um dos tratamentos anteriores).

Nos tratamentos $T_{1}, T_{2}$ e $T_{3}$, a água foi acondicionada em copos-de-Becker de $250 \mathrm{~mL}$ e aquecida em estufa até atingir a temperatura de $80^{\circ} \mathrm{C}$. Neste ambiente, as sementes foram colocadas em imersão, assim permanecendo durante o período necessário ao tratamento. Após, foram retiradas da água e colocadas em papel absorvente para remoção do excesso de umidade.

Nos tratamentos de $\mathrm{T}_{4}, \mathrm{~T}_{5}$ e $\mathrm{T}_{6}$, o álcool foi colocado em copos-de-Becker de $100 \mathrm{~mL}$, onde, em seguida, foram colocadas as sementes, que permaneceram em imersão à temperatura ambiente. Após o período necessário para o tratamento, as sementes foram retiradas do álcool e colocadas sobre papel absorvente, para retirar o excesso de álcool.

Nos tratamentos de $T_{7}, T_{8}$ e $T_{9}$, foram utilizados copos-de-Becker, para colocar as sementes em contato com o ácido sulfúrico concentrado por 3, 6 e 9 minutos. Após cada tempo de exposição, as sementes foram retiradas dos recipientes e, com o auxílio de uma peneira, lavadas com água corrente para eliminar a ação do produto.

Para detectar o efeito dos tratamentos estudados, foi realizado o teste de germinação, conforme Regras para Análise de Sementes (Brasil, 1992). A germinação foi realizada em um germinador de câmara; a temperatura foi mantida em $25^{\circ} \mathrm{C}$, e a umidade relativa do ar, entre $95 \mathrm{e}$ $98 \%$; o substrato utilizado foi o papel Germitest; as sementes foram embrulhadas em forma de rolo e colocadas no germinador, na posição vertical; o papel foi esterilizado em estufa regulada para $70^{\circ} \mathrm{C}$, durante 4 horas. Os equipamentos e utensílios utilizados foram desinfetados antes de sua utilização. Após um período de 5 dias de permanência das sementes na estufa germinadora, foram feitas as leituras.

O delineamento estatístico utilizado para o teste de germinação foi o inteiramente casualizado, em arranjo fatorial 4 (cultivares) x 10 (tratamentos), com 4 repetições de 50 sementes. Os valores referentes à porcentagem de germinação foram previamente transformados em arc sen $\sqrt{\% / 100}$, para normalizar a sua distribuição e para comparar as possíveis diferenças entre os tratamentos foi aplicado o teste de Tukey a $5 \%$ de probabilidade. 


\section{RESULTADOS E DISCUSSÃO}

As sementes do feijão-mungo submetidas ao tratamento de imersão em água a $80^{\circ} \mathrm{C}$ por 5 minutos obtiveram a maior porcentagem de germinação. $\mathrm{O}$ tratamento de 10 minutos, quando comparado à testemunha, ainda apresentou bons resultados; entretanto, o de 15 minutos danificou seriamente as sementes testadas (Tabela 1).

Bakke \& Gonçalves (1984) concluíram que a imersão em água fervente por 6 segundos foi tratamento eficiente para superar a dormência de sementes de algaroba. Para a bracatinga, Bianchetti (1981) recomendou, para superar a dormência, a imersão em água quente de 70 a $96^{\circ} \mathrm{C}$, deixando-se as sementes em repouso nesta água, sem aquecimento, por 18 horas.

O presente resultado, juntamente com os resultados obtidos por Bianchetti (1981) e Bakke \& Gonçalves (1984), comprovam a eficiência dos tratamentos com água quente para superar a dormência de sementes de algumas espécies. No entanto, tais tratamentos não devem ser utilizados indiscriminadamente, para quaisquer espécies de sementes, haja vista os resultados obtidos por Martins et al. (1992), nos quais as sementes de sabiá, com e sem casca, submetidas aos tratamentos de imersão em água a $100^{\circ} \mathrm{C}$ por 3 e 5 minutos apresentaram-se mortas e totalmente recobertas de fungo 5 dias após a instalação do teste padrão de germinação. Maeda \& Lago (1986) também mostraram que a imersão das sementes de mucuna-preta em água fervente, por
1 minuto, causou a morte de praticamente todas as sementes. A temperatura da água e o período do tempo de imersão foram fatores importantes que determinaram o sucesso ou não da superação da dormência das sementes.

Os tratamentos de controle apresentaram percentuais de germinação de $37 \%$ na cultivar NM 51 (menor valor), e de $83 \%$ na cultivar Chun Nam 4 (maior valor). As cultivares Pusa 9173 e ML 267 apresentaram percentuais de germinação intermediários, de 60 e $58 \%$, respectivamente. A imersão em água, à temperatura de $80^{\circ} \mathrm{C}$ por $5 \mathrm{mi}$ nutos, foi eficiente para superar a dormência das sementes de todas as cultivares; porém, a imersão por 15 minutos mostrou-se prejudicial à germinação das sementes, já que todas as cultivares submetidas a este período de tratamento tiveram seus percentuais de germinação drasticamente reduzidos (Tabela 1).

As sementes do feijão-mungo, submetidas ao tratamento de imersão em álcool, à temperatura ambiente, por 5, 10 e 15 minutos, apresentaram percentuais de germinação semelhantes entre si e maiores que os da testemunha (Tabela 2). Este resultado demonstrou que o tratamento com imersão em álcool à temperatura ambiente favoreceu a germinação das sementes do feijão-mungo.

As sementes da cultivar Chun Nam 4, imersas em álcool, não obtiveram benefício para a sua germinação neste experimento. Entretanto, as cultivares Pusa 9173, NM 51 e ML 267 elevaram seus percentuais de germinação para 83 a 90\%, após te-

TABELA 1. Porcentagens de germinação das sementes de 4 cultivares de feijão-mungo que foram submetidas à imersão em água à temperatura de $80^{\circ} \mathrm{C}$, por $5,10 \mathrm{e} 15$ minutos. CCA/UFSC, $1994^{1}$.

\begin{tabular}{|c|c|c|c|c|c|}
\hline \multirow{2}{*}{$\begin{array}{l}\text { Tempo de imersão } \\
\text { (minuto) }\end{array}$} & \multicolumn{5}{|c|}{ Porcentagens de germinação ${ }^{2}$} \\
\hline & Pusa 9173 & NM 51 & ML 267 & Chun Nam 4 & Média \\
\hline Testemunha & $60 \mathrm{bB}$ & $37 \mathrm{bC}$ & $58 \mathrm{bB}$ & $83 \mathrm{bA}$ & $60 c$ \\
\hline 5 & $91 \mathrm{aA}$ & $82 \mathrm{aB}$ & $91 \mathrm{aA}$ & $94 \mathrm{aA}$ & $90 a$ \\
\hline 10 & $92 \mathrm{aA}$ & $78 \mathrm{aB}$ & $84 \mathrm{aB}$ & $77 \mathrm{bB}$ & $83 b$ \\
\hline 15 & $06 \mathrm{cB}$ & $09 \mathrm{cB}$ & $05 \mathrm{cB}$ & $21 \mathrm{cA}$ & $10 \mathrm{~d}$ \\
\hline Média & $62 \mathrm{~B}$ & $52 \mathrm{C}$ & $60 \mathrm{~B}$ & $69 \mathrm{~A}$ & \\
\hline
\end{tabular}


rem sido submetidas ao tratamento de imersão em álcool à temperatura ambiente por 5, 10 e 15 minutos (Tabela 2).

Os tratamentos com imersão em ácido sulfúrico concentrado por 3, 6 e 9 minutos, os quais não apresentaram diferenças estatísticas, foram muito eficientes para a germinação das sementes do feijãomungo, resultando em médias de 95,96 e $95 \%$ de germinação, respectivamente (Tabela 3 ).

Os percentuais de germinação das sementes das cultivares tratadas com ácido sulfúrico neste experimento, exceto para Chun Nam 4, foram muito maiores que os das testemunhas. Os resultados indicaram que a imersão em ácido sulfúrico concentrado, por 3 minutos, foi eficiente, já que o aumento do tempo de exposição até 9 minutos não proporcionou aumentos significativos (Tabela 3 ).

Analisando os resultados contidos na Tabela 4, observa-se que a maior porcentagem de germina- ção foi obtida utilizando-se a imersão das sementes em ácido sulfúrico concentrado, por 6 minutos $\left(\mathrm{T}_{8}\right)$; a imersão por 9 minutos $\left(\mathrm{T}_{9}\right)$ e por 3 minutos $\left(\mathrm{T}_{7}\right)$ também mostraram excelentes resultados. Os tratamentos com imersão em álcool à temperatura ambiente, por 5,10 e 15 minutos $\left(\mathrm{T}_{4}, \mathrm{~T}_{5}\right.$ e $\left.\mathrm{T}_{6}\right)$, e com imersão em água à temperatura de $80^{\circ} \mathrm{C}$, por $5 \mathrm{e}$ 10 minutos $\left(\mathrm{T}_{1}\right.$ e $\left.\mathrm{T}_{2}\right)$, mostraram-se tratamentos pré-germinativos eficientes, atingindo um percentual de germinação superior à testemunha $\left(\mathrm{T}_{10}\right)$. No tratamento de imersão em água a $80^{\circ} \mathrm{C}$, por 15 minutos $\left(\mathrm{T}_{3}\right)$, verificou-se acentuada mortalidade de sementes, o que resultou em drástica redução no percentual de germinação.

Passos et al. (1988), estudando um método simples e eficiente para acelerar e uniformizar a germinação das sementes de leucena, constataram que os tratamentos com ácido sulfúrico (95\%) foram os que apresentaram maiores porcentagens de germinação.

TABELA 2. Porcentagens de germinação das sementes de 4 cultivares de feijão-mungo que foram submetidas à imersão em álcool à temperatura ambiente, por 5, 10 e 15 minutos. CCA/UFSC, 1994.

\begin{tabular}{cccccc}
\hline \multirow{2}{*}{$\begin{array}{c}\text { Tempo de imersão } \\
\text { (minuto) }\end{array}$} & Pusa 9173 & NM 51 & ML 267 & Chun Nam 4 & Média \\
\cline { 2 - 6 } & $60 \mathrm{bB}$ & $37 \mathrm{bC}$ & $58 \mathrm{bB}$ & $83 \mathrm{aA}$ & $60 \mathrm{~b}$ \\
Testemunha & $83 \mathrm{aA}$ & $83 \mathrm{aA}$ & $89 \mathrm{aA}$ & $90 \mathrm{aA}$ & $86 \mathrm{a}$ \\
5 & $88 \mathrm{aA}$ & $83 \mathrm{aA}$ & $89 \mathrm{aA}$ & $8 \mathrm{aA}$ & $8 \mathrm{a}$ \\
10 & $83 \mathrm{aA}$ & $90 \mathrm{aA}$ & $80 \mathrm{aA}$ & $80 \mathrm{a}$ & $8 \mathrm{a}$ \\
\hline Média & $79 \mathrm{~B}$ & $73 \mathrm{C}$ & $82 \mathrm{~B}$ & & $88 \mathrm{~A}$ \\
\hline
\end{tabular}

${ }^{1}$ Médias seguidas da mesma letra minúscula (na coluna) e maiúscula (na linha) não diferem entre si a $5 \%$ de probabilidade, pelo teste de Tukey.

${ }^{2}$ Dados transformados em arc sen $\sqrt{\% / 100}$ para a análise estatística; são apresentadas as médias não transformadas.

TABELA 3. Porcentagens de germinação das sementes de 4 cultivares de feijão-mungo que foram submetidas à imersão em ácido sulfúrico concentrado por 3, 6 e 9 minutos. CCA/UFSC, 19941 .

\begin{tabular}{cccccc}
\hline \multirow{2}{*}{$\begin{array}{c}\text { Tempo de imersão } \\
\text { (minuto) }\end{array}$} & Pusa 9173 & NM 51 & ML 267 & Chun Nam 4 & Média \\
\cline { 2 - 6 } & $60 \mathrm{bB}$ & $37 \mathrm{bC}$ & $58 \mathrm{bB}$ & $83 \mathrm{bA}$ & $60 \mathrm{~b}$ \\
Testemunha & $95 \mathrm{aA}$ & $95 \mathrm{aA}$ & $93 \mathrm{aA}$ & $96 \mathrm{aA}$ & $95 \mathrm{a}$ \\
3 & $96 \mathrm{aA}$ & $96 \mathrm{aA}$ & $97 \mathrm{aA}$ & $92 \mathrm{aA}$ & $96 \mathrm{a}$ \\
6 & $97 \mathrm{aA}$ & $97 \mathrm{aA}$ & $93 \mathrm{aA}$ & $92 \mathrm{~A}$ \\
\hline
\end{tabular}

${ }_{1}^{1}$ Médias seguidas da mesma letra minúscula (na coluna) e maiúscula (na linha) não diferem entre si a $5 \%$ de probabilidade, pelo teste de Tukey.

${ }^{2}$ Dados transformados em arc sen $\sqrt{\% / 100}$ para a análise estatística; são apresentadas as médias não transformadas. 
O tratamento com ácido sulfúrico por 4 minutos possibilitou uma porcentagem de germinação de 99,0\%, sendo assim o mais indicado. Nóbrega et al. (1991) também descobriu que, para a quebra de dormência em sementes de Cassia grandis, o melhor método de tratamento é a imersão das sementes em ácido sulfúrico durante 30 minutos.

Dentre as sementes utilizadas no experimento, verificou-se maior intensidade de dormência nas cultivares que possuem sementes de menor tamanho, sendo elas Pusa 9173, ML 267 e NM 51. A cultivar Chun Nam 4, por possuir sementes de maior tamanho, apresentou menor intensidade de dormência. Segundo Nimer et al. (1983), o maior grau de dormência da semente de mucuna-preta seria sobre as sementes de menor tamanho, quando comparadas ao padrão normal. O peso de mil sementes das cultivares Pusa 9173, ML 267, NM 51 e Chun Nam 4 foi de 45 g, 34 g, 40 g e 53 g, respectivamente.

O tratamento com ácido sulfúrico apresentou os melhores resultados, mas a sua realização torna-se perigosa, pois é grande o risco de acidentes que poderiam resultar em queimaduras, além do problema de que o tratamento origina resíduos poluentes das

TABELA 4. Porcentagem de germinação em função dos tratamentos pré-germinativos aplicados às sementes do feijão-mungo. CCA/UFSC, 1994.

\begin{tabular}{lc}
\hline Tratamento & $\begin{array}{c}\text { Porcentagem de } \\
\text { germinação }\end{array}$ \\
\hline $\mathrm{H}_{2} \mathrm{SO}_{4}$ concentrado, 6 minutos & $96 \mathrm{a}$ \\
$\mathrm{H}_{2} \mathrm{SO}_{4}$ concentrado, 9 minutos & $95 \mathrm{a}$ \\
$\mathrm{H}_{2} \mathrm{SO}_{4}$ concentrado, 3 minutos & $95 \mathrm{a}$ \\
Água, $80^{\circ} \mathrm{C}, 5$ minutos & $90 \mathrm{~b}$ \\
Álcool, temp. ambiente, 15 minutos & $88 \mathrm{~b}$ \\
Álcool, temp. ambiente, 10 minutos & $87 \mathrm{bc}$ \\
Álcool, temp. ambiente, 5 minutos & $86 \mathrm{bc}$ \\
Água, $80^{\circ} \mathrm{C}, 10$ minutos & $83 \mathrm{c}$ \\
Testemunha & $60 \mathrm{~d}$ \\
Água, $80^{\circ} \mathrm{C}, 15$ minutos & $10 \mathrm{e}$ \\
\hline Média & 79 \\
DMS $(5 \%)$ & 5 \\
C.V. $(\%)$ & 33 \\
\hline 1 & \\
1 &
\end{tabular}

águas. Por outro lado, o tratamento com álcool mostrou-se quase tão eficiente quanto o que utilizou ácido sulfúrico. A vantagem do álcool reside na sua facilidade de aplicação, a qual não apresenta perigo para o aplicador do tratamento, pois o resíduo do álcool pode ser utilizado em outras práticas.

\section{CONCLUSÕES}

1. Dentre os tratamentos testados, a imersão em ácido sulfúrico concentrado por 6 minutos é o mais indicado.

2. A imersão em álcool à temperatura ambiente, apesar de não ser o tratamento mais eficiente, pode ser utilizada satisfatoriamente, e é de fácil realização.

3. O tratamento com ácido sulfúrico apresenta os melhores resultados, mas é grande o risco de acidentes, que podem resultar em queimaduras.

4. O tratamento de imersão em água a $80^{\circ} \mathrm{C}$ por 5 minutos mostra-se um método eficiente. Mas a imersão por 15 minutos danifica seriamente as sementes testadas.

5. Das sementes utilizadas no experimento, verifica-se maior intensidade de dormência nas cultivares que possuem sementes de menor tamanho.

\section{REFERENCIAS}

BAKKE, O.A.; GONÇALVES, W. Quebra de dormência em algaroba. In: SIMPÓSIO INTERNACIONAL: MÉTODOS DE PRODUÇÃO E CONTROLE DE QUALIDADE DE SEMENTES E MUDAS FLORESTAIS. 1984, Curitiba, PR. Anais... Curitiba: UFPR, 1984. p.65-69.

BIANCHETTI, A. Produção e tecnologia de sementes de essências florestais. In: SEMINÁRIO DE SEMENTES E VIVEIROS FLORESTAIS, 1., 1981, Curitiba, PR. Anais... Curitiba: FUPEF, 1981. v.1, p.13.

BRASIL. Ministério da Agricultura e Reforma Agrária. Regras para análise de sementes. Brasília, 1992. $365 \mathrm{p}$.

DUQUE, F.F.; SOUTO, S.M.; ABBOUD, A.C. Mungo, proteína em forma de broto de feijão. A Lavoura, Rio de Janeiro, v.90, p.21-23, abr/jun., 1987. 
LIN, S.S.; FERRARI, R. Efeito do envelhecimento de sementes sobre a qualidade fisiológica das sementes do feijão-mungo (Vigna radiata L.). Informativo ABRATES, v.3, n.3, p.42, 1993.

MAEDA, J.A.; LAGO, A.A. Germinação de sementes de mucuna preta após tratamento para superação da impermeabilidade do tegumento. Revista Brasileira de Sementes, Brasília, v.8, n.1, p.79-86, 1986.

MARTINS, C.C.; CARVALHO, N.M.; OLIVEIRA, A.P. Quebra de dormência de sementes de sabiá (Mimosa caesalpiniaefolia BENTH.) Revista Brasileira de Sementes, Brasília, v.14, n.1, p.5-8, 1992.

NIMER, N.M.; CARVALHO, N.M.; LOUREIRO, N.; PERECIN, D. Influência de alguns fatores da planta sobre o grau de dormência em sementes de mucuna-preta. Revista Brasileira de Sementes, Brasília, v.5, n.2, p.111-119, 1983.

NÓBREGA, L.H.P.; AMARAL, A.L.P.; DEMATTÊ, M.E.S.P. Métodos para quebra de dormência em sementes de Cassia grandis. Informativo ABRATES, v.1, n.4, p.83, 1991.

PASSOS, M.A.A.; LIMA, T.V. de; ALBUQUERQUE, J.L. Quebra de dormência em sementes de leucena. Revista Brasileira de Sementes, Brasília, v.10, n.2, p.97-102, 1988.

TOLEDO, F.F.; MARCOS FILHO, J. Manual das sementes: tecnologia da produção. São Paulo: Agronômica Ceres, 1977. 224p. 